
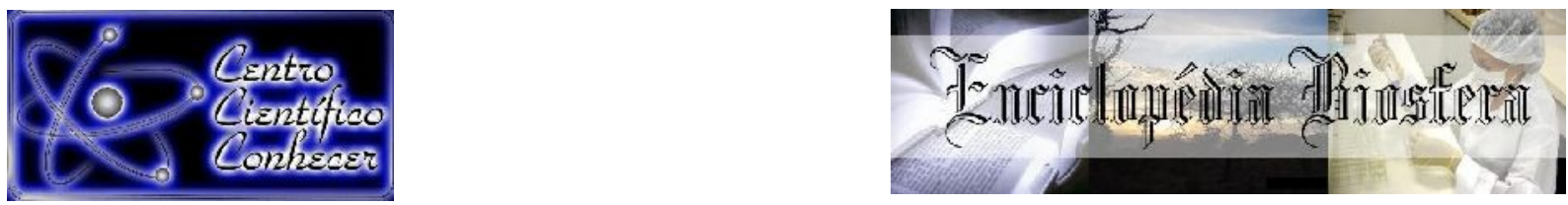

\title{
DIAGNÓSTICO DE PATOLOGIAS ENCONTRADAS EM PAVIMENTOS RODOVIÁRIOS FLEXÍVEIS E SEMIRRÍGIDOS
}

\author{
Jorcelan Pereira da Rocha ${ }^{1}$, Lucas Galvão Cunha Monteiro Ferreira ${ }^{2}$, Fernando \\ Vasconcelos Borba ${ }^{3}$
}

1 Engenheiro civil. Pós-graduando em Infraestrutura de Transportes e Rodovias pelo Instituto de graduação e pós-graduação - IPOG (jorcelan20@gmail.com) Barreirinhas, Maranhão, Brasil.

2 Engenheiro civil. Pós-graduando em Infraestrutura de Transportes e Rodovias pelo Instituto de graduação e pós-graduação - IPOG - São Luís, Maranhão, Brasil. 3 Engenheiro civil. Mestrando em Estruturas e Construção Civil pela Universidade Federal do Pará UFPA - Belém, Pará, Brasil.

\section{Recebido em: 04/10/2019 - Aprovado em: 30/11/2019 - Publicado em: 15/12/2019} DOI: 10.18677/EnciBio_2019B22

\begin{abstract}
No Brasil, existe uma grande dependência do setor rodoviário, o que contribuiu para o surgimento de extensa malha de vias pavimentadas. Entretanto, devido à falta de investimentos em atividades de Manutenção e Restauração (M\&R) os números de patologias estão gradativamente aumentando, deteriorando as estruturas existentes, ocasionando desconforto e diminuindo a segurança dos usuários das rodovias. Assim, o presente artigo teve por objetivo descrever as principais patologias encontradas nos pavimentos flexíveis e semirrígidos e, ainda, as atividades de $M \& R$ utilizadas para restruturação de rodovias danificadas. Para obtenção dos resultados foi realizado uma revisão bibliográfica que engloba as principais informações sobre o tema em análise, destacando-se também, a apreciação de notícias sobre o setor rodoviário que possam contribuir para um maior entendimento sobre as novas pesquisas no panorama nacional, pois é notório que tais problemas são importantíssimos na atualidade pelo fato de que a falta de intervenções vêm causando um desperdício imensurável do dinheiro público. Dessa maneira, conclui-se que o presente estudo contribui com a comprovação da importância da manutenção de qualidade de vias pavimentadas em todo o país, tornando de forma mais simples a verificação das patologias por estudantes de engenharia que farão pesquisas com auxílio das informações apresentadas neste trabalho.
\end{abstract}

PALAVRAS-CHAVE: Manutenção e Restauração (M\&R). Pavimentos flexíveis e semirrígidos .Patologia. 


\title{
DIAGNOSIS OF PATHOLOGIES FOUND IN FLEXIBLE AND SEMI-RIGID ROAD PAVEMENTS
}

\begin{abstract}
In Brazil, there is a heavy dependence on the road sector, which has contributed to the emergence of an extensive network of paved roads. However, due to the lack of investments in Maintenance and Restoration (M\&R) activities, the numbers of pathologies are gradually increasing, deteriorating existing structures, causing discomfort and reducing the safety of highway users. Thus, this article aims to describe the main pathologies found in flexible and semi-rigid pavements and also the $M \& R$ activities used to restructure an affected stretch. In order to obtain the results, a bibliographic review was carried out that includes the main information on the subject under analysis, highlighting also the appreciation of news about the road sector that may contribute to a greater understanding of the new research in the national panorama, as it is It is notorious that such problems are very important today because the lack of interventions has been causing immeasurable waste of public money. Thus, it is concluded that the present study contributes to prove the importance of maintaining quality of paved roads throughout the country, making it easier to verify the pathologies by engineering students who will do research with the help of the information presented in this work.
\end{abstract}

KEYWORDS: Pathology. Maintenance and Restoration (M\&R). Flexible and semirigid Pavements.

\section{INTRODUÇÃO}

A condição do pavimento das rodovias está relacionada diretamente com o desempenho do modal rodoviário e da economia brasileira, pois tais características podem causar prejuízos financeiros e ambientais em escala elevada. Assim, uma via que apresenta patologias, eleva o custo operacional do transporte, diminui o conforto e a segurança dos passageiros e das cargas. Apesar disso, de acordo com a última pesquisa realizada pela Confederação Nacional de Transportes (CNT) em 2018, 50\% dos aproximados 106 mil quilômetros de rodovias apresentam defeitos, ou seja, a condição foi considerada como regular, ruim ou péssima (CNT, 2018a).

Apesar da elevada quantidade de rodovias pavimentadas federais, estaduais e municipais, existe uma dependência em todo o Brasil de uma reestruturação da malha rodoviária, devendo ser melhorada, em grande escala, por serviços de construção, pavimentação e duplicação. Ou seja, a maioria das rodovias presentes no cenário brasileiro está fora de um padrão de aceitabilidade, pois são diversos os problemas localizados não só em vias pavimentadas, mas também, nas não pavimentadas (CNT, 2018c).

Dessa forma, destaca-se que um importante componente dos pavimentos, o asfalto é aplicado em mais de $99 \%$ dos segmentos pavimentados no Brasil, compondo os pavimentos flexíveis e semirrígidos. Entretanto, tais estruturas apresentam problemas em maior escala em comparação com os pavimentos de concreto, o que afeta os veículos, aumenta o consumo de combustível e o tempo 
das viagens, ocasionando a elevação do custo operacional do transporte, intervindo no preço dos produtos consumidos pela população (CNT, 2019).

Concomitantemente, DYNATEST (2017) cita que a durabilidade de uma rodovia está relacionada a três elementos: preparação de um bom projeto, que mencione as camadas do pavimento segundo a realidade do local e volume de tráfego; desempenho satisfatório das obras, com fiscalização da qualidade dos serviços e materiais empregados e, ainda, manutenção preventiva e corretiva do pavimento. Dificuldades na aplicação desses passos ocasionarão em patologias antecipados nas vias. Assim, os principais tipos de defeitos no pavimento são classificados, em geral, em trincamentos, fissuras, exsudação, desagregação, deformações, panelas e remendos (CNT, 2017).

Após o surgimento das patologias, de acordo com Adlinge e Gupta (2013), a umidade pode enfraquecer expressivamente a resistência dos materiais utilizados nas camadas do pavimento e, também, do subleito. Porquanto, a umidade pode entrar na estrutura do pavimento através de trincas e orifícios na superfície, lateralmente através do subleito e do lençol freático subjacente por capilaridade. Isso ocasiona a lubrificação, perda de intertravamento e deslocamento das partículas, ou seja, resultando na falha do pavimento.

Zofka (2018) cita que deve existir uma estratégia proativa para os pavimentos mais novos antes de atingirem uma deterioração significativa. Essa estratégia deve ser definida e incorporada às ferramentas de planejamento, com a finalidade de determinar após a construção de novas rodovias a alocação objetiva de financiamento entre redes mais novas e mais antigas, usando o planejamento do ciclo de vida.

O presente trabalho teve como objetivo elucidar de forma simples e clara as principais patologias encontradas em pavimentos flexíveis e semirrígidos através de uma revisão bibliográfica, principalmente, as normas do Departamento Nacional de Infraestrutura de Transportes - DNIT, livros, publicações científicas e pesquisas em sites da Confederação Nacional de transportes - CNT. Ou seja, a finalidade foi reconhecer os principais defeitos localizados em rodovias pavimentadas, assim como entender as características das atividades de Manutenção e Restauração (M\&R) para cada uma das patologias descritas.

\section{PAVIMENTOS}

Segundo Balbo (2007), pavimentar é obra de construção civil que tem como objetivo a melhoria operacional para o tráfego, obtenção de uma superfície: Regular que proporciona melhor conforto para o usuário da via; aderente que seja capaz de prover mais segurança em dias em que a rodovia estiver úmida ou molhada; e menos ruidosa diante da movimentação dos pneus apta a gerar conforto ambiental mais elevado em vias urbanas e rurais.

Do mesmo modo, o DNIT (2006a) afirma que o pavimento rodoviário é uma superestrutura composta por camadas de espessuras predeterminadas, sobrepostas em um espaço ilimitado, ao qual é denominado de subleito. Sendo assim, a estrutura precisa atender os seguintes critérios:

a. Suportar e distribuir ao terreno de fundação as tensões geradas pelo tráfego; 
b. Elevar a qualidade de rolamento no que se refere à comodidade e conforto;

c. Suportar os esforços horizontais (desgaste), possibilitando maior durabilidade à capa de rolamento.

Conforme mencionado anteriormente, o pavimento é composto por diversas camadas, estas utilizam diferentes materiais com objetivo de alcançar determinada rigidez, assim, considerando a rigidez obtida para a estrutura dos pavimentos, é possível classificá-los em flexível, semirrígido e rígido. Na figura 1 observa-se a seção longitudinal de um pavimento flexível ou semirrígido (DNIT, 2006a).

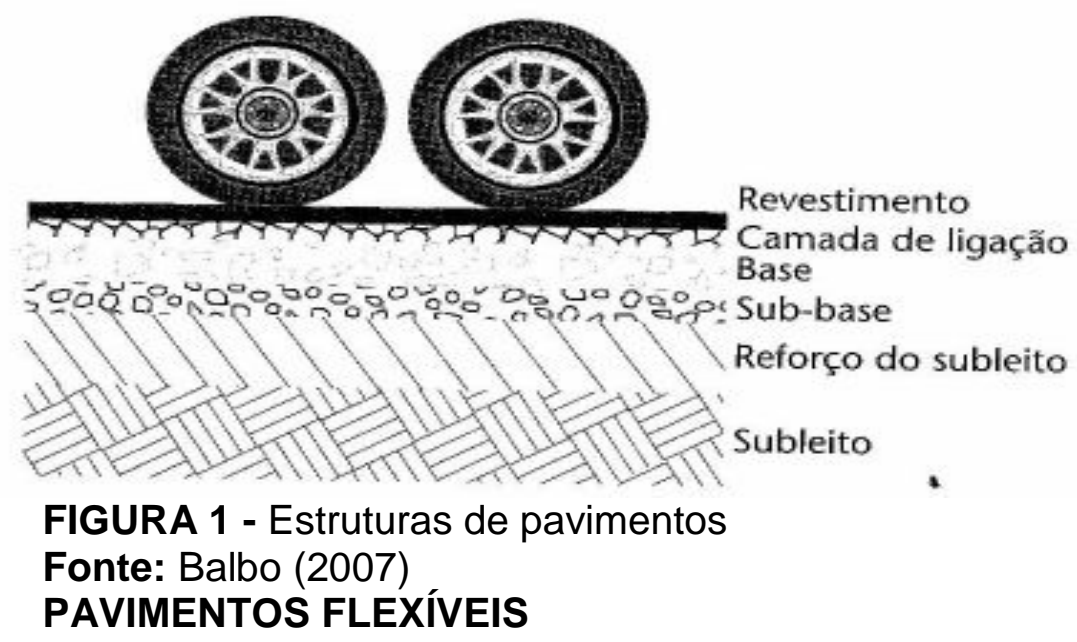

São pavimentos em que deformações elásticas acorrem em todas as camadas, quando exposto a tensões na superfície e, portanto, o carregamento se alastra de forma aproximadamente igual em toda a superestrutura. Geralmente são estruturas formadas por revestimento asfáltica, por uma base granular ou por uma base de solo pedregulhoso, sub-base, reforço do subleito e regularização do subleito que não é apontada como uma camada do pavimento (DNIT, 2006a).

\section{PAVIMENTOS SEMIRRÍGIDOS}

Pavimentos caracterizados por possuírem revestimento asfáltico e uma camada (base ou sub-base) composta por material estabilizado com ligante hidráulico, não havendo a utilização de uma camada de concreto, levando em consideração a rigidez, os pavimentos semirrígidos devem apresentar comportamento intermediário entre pavimentos rígidos e flexíveis (BALBO, 2007). Igualmente, o pavimento semirrígido segundo DNIT (2006a), caracteriza-se por possuir a base ou sub-base cimentada por materiais com propriedades aglutinantes como a cal, o cimento e alguns materiais betuminosos.

\section{PAVIMENTOS RÍGIDOS}

Nos pavimentos rígidos o revestimento tem alto grau de rigidez em comparação às camadas inferiores e, portanto, a maior parte do carregamento 
aplicado (tensões) é absorvida praticamente em por essa camada. Geralmente são estruturas formadas por lajes de concreto de cimento Portland, que tem a função simultânea de revestimento e base do pavimento (DNIT, 2006a).

Balbo (2007) cita que a resposta estrutural do pavimento rígido ocorre com um campo de tensão bem mais disperso, ou seja, a carga é distribuída semelhantemente em toda a dimensão da placa de concreto, o que proporciona menores esforços verticais gerados sobre o subleito.

\section{CAMADAS DOS PAVIMENTOS}

Como já mencionado, o pavimento, por motivo técnico e econômico é formado por camadas de diferentes resistências e deformabilidades, originando assim, uma grande dificuldade quanto ao cálculo de tensões e deformações (DNIT, 2006a). Em conformidade com Balbo (2007), a estrutura do pavimento é idealizada com finalidade exclusivamente estrutural, ou seja, para receber e transmitir esforços, possibilitando aliviar pressões sobre as camadas subjacentes, que possuem menos resistência na maioria das vezes. Para o funcionamento estrutural da rodovia, todas as camadas devem trabalhar deformações compatíveis com a sua natureza e capacidade de carga, devendo evitar que aconteçam processos de ruptura ou danificação rápida e inadvertida nos materiais que as compõem.

Assim, o material mais forte (menos flexível) se encontra na camada superior e o material mais fraco (mais flexível) se encontra na camada inferior. A causa disso é que, na superfície, a carga gerada pela locomoção dos veículos é aplicada a uma área pequena, os resultados são altos níveis de tensão, mais fundo no pavimento, a carga da roda é aplicada a uma área maior, o resultado são níveis de tensão mais baixos, permitindo uso de materiais mais fracos (ADLINGE; GUPTA, 2013).

As camadas que formam um pavimento têm funções específicas de acordo com suas características e são denominadas como: revestimento, base, sub-base, reforço do subleito e regularização do subleito que não é classificada como uma camada da estrutura do pavimento. No entanto, em algumas situações, o pavimento não possuirá camadas de sub-base ou de reforço, porque tais camadas servem para auxiliar a base e ao subleito respectivamente (BALBO, 2007).

\section{REVESTIMENTO}

Balbo (2007) menciona que o revestimento é a camada do pavimento que fica em contato direto com as rodas dos veículos, isto é, deverá entre outras funções receber esforços estáticos ou dinâmicos, sem ter amplas deformações elásticas ou plásticas, desagregação de elementos ou, ainda, perda de compactação. Os materiais que integra o revestimento devem estar bem aglutinados ou arranjados de modo a evitar o deslocamento horizontal. Na Figura 2 são anotados os principais materiais utilizados como revestimentos flexíveis e rígidos. 


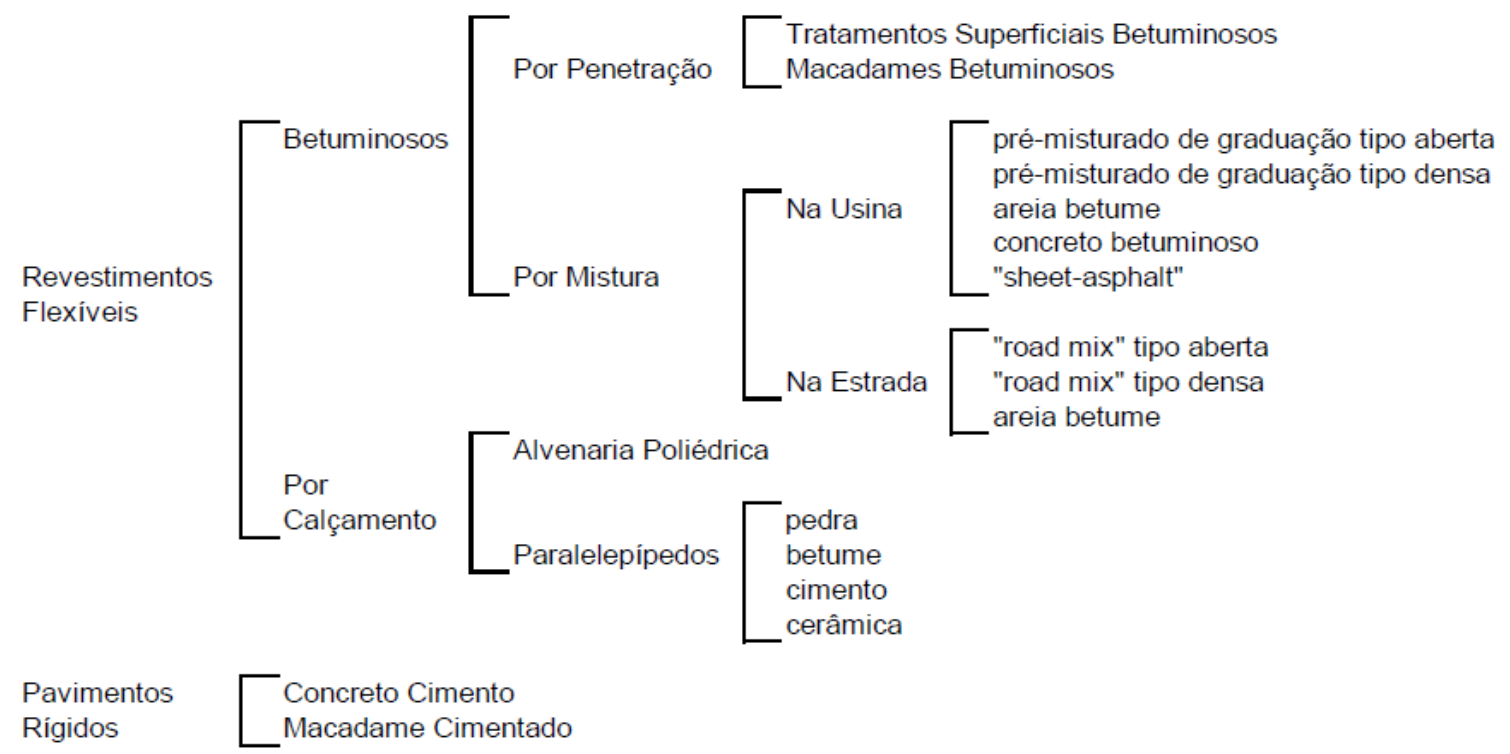

FIGURA 2 - Tipos de revestimentos rígidos e flexíveis Fonte: DNIT (2005)

A. REVESTIMENTOS FLEXÍVEIS;

Os revestimentos flexíveis podem ser betuminosos e por calçamento. Os revestimentos betuminosos são formados pela mistura de agregados e materiais betuminosos, e sua aplicabilidade é a que mais se desenvolveu no território brasileiro por fatores econômicos. Geralmente os revestimentos asfálticos são subdivididos em duas ou mais camadas por motivos técnicos, construtivos e orçamentários. Essa subdivisão do revestimento em camadas é denominada de camada de rolamento e camada de ligação ou do inglês "Binder" (BALBO, 2007).

Levando em consideração os revestimentos flexíveis por calçamento, DNIT (2006a) menciona que a sua utilização em rodovias diminuiu proporcionalmente com o aumento da utilização de pavimentos asfálticos e de concreto. Por isso, o uso encontrar-se cada vez mais limitado a pátios de estacionamento, vias urbanas e alguns acessos viários.

B. REVESTIMENTOS RÍGIDOS;

Os revestimentos rígidos são constituídos por concreto de cimento, ou seja, é uma combinação que necessita de grande utilização de cimento Portland, areia, agregado graúdo e água, distribuídos em uma camada devidamente adensada, sendo que, tal camada tem a função conjunta de revestimento e base do pavimento (DNIT, 2006a). Assim, percebe-se que o revestimento rígido é de fundamental importância para obtenção de uma via com melhores propriedades, entretanto, a aplicação em rodovias nacionais ainda não se desenvolveu como deveria (DNIT, 2006a). 


\section{BASE E SUB-BASE}

$\mathrm{Na}$ Figura 3 estão evidenciadas as diferentes bases e sub-bases de pavimentos flexíveis e semirrígidos.

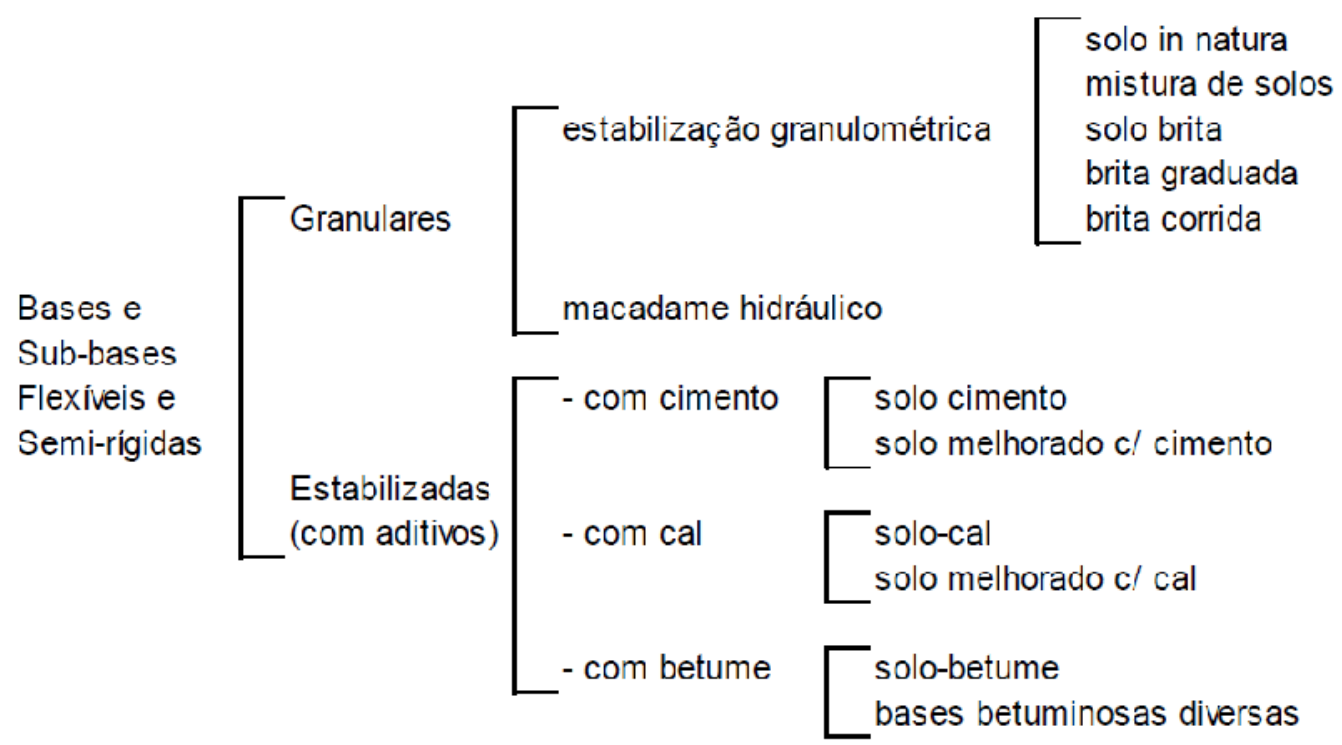

FIGURA 3 - Bases e sub-bases flexíveis e semirrígidas

Fonte: DNIT (2005)

Lembrando que dependendo das tensões atuantes, ao desempenhar a função de distribuir esforços, a camada de base poderá se apresentar de forma grossa, portanto, por razões de natureza técnica e econômica, deve-se dividir a base em duas camadas, gerando-se, assim, uma sub-base usualmente com um menor valor econômico. Assim, as camadas de bases e sub-bases, têm a função de aliviar os esforços nas camadas de solos inferiores e podem exercer papel importante na drenagem superficial dos pavimentos (BALBO, 2007).

\section{REFORÇO DO SUBLEITO}

O reforço do subleito é uma camada de espessura constante, executada por motivo técnico e econômico sobre a regularização do subleito, com propriedades dos materiais empregados superiores às do subleito e inferiores as camadas que se encontram em posição mais elevada (DNIT, 2006a).

Conjuntamente, Balbo (2007) menciona que a utilização da camada de reforço de subleito não é obrigatória. Todavia, para evitar que alguns tipos de pavimentos, principalmente os flexíveis, tenham camadas muito espessas de base e sub-base, usa-se o reforço, sendo menos oneroso em comparação a maiores espessuras de camadas granulares ou cimentadas.

\section{REGULARIZAÇÃO DO SUBLEITO}

Conforme constatado por DNIT (2006a), a regularização do subleito surge com a necessidade de conformação do terreno de forma transversal e longitudinal, 
sendo executada de acordo com especificações técnicas. No entanto, a regularização não é classificada como uma camada do pavimento e pode-se dizer que a função primordial é uma atividade reduzida em corte do leito implantado ou em sobreposição a este, formando assim, uma "camada" com espessura variável.

\section{SUBLEITO}

O subleito é o terreno de fundação limitado superiormente pelas camadas do pavimento e estimado até a profundidade em que as tensões provocadas pelo tráfego agem de maneira expressiva (DNIT, 2006a). Para Balbo (2007) as tensões aplicadas sobre o subleito se dissipam no primeiro metro de profundidade. Então, deve-se ter maior atenção com as camadas superiores, porquanto as tensões atuantes sobre essas, são mais intensas e já chegam minimizadas ao subleito.

\section{PATOLOGIAS EM PAVIMENTOS FLEXÍVEIS E SEMIRRÍGIDOS}

Os defeitos podem se apresentar sobre a rodovia por diversos motivos, porém, erros de projeto e execução podem contribuir para o surgimento ou desenvolvimento de patologias que irão prejudicar a funcionalidade da rodovia. Estas, no território brasileiro, são executadas com pavimentos flexíveis e semirrígidos, assim, serão definidos a seguir os principais problemas encontrados para esses tipos de pavimentos (CNT, 2018a).

\section{TRINCA TRANSVERSAL}

É uma trinca isolada que se manifesta, geralmente, perpendicular ao eixo da via. Sendo que, quando essa trinca aparecer com extensão de até um metro é chamada trinca transversal curta e quando a extensão for superior a um metro é chamada trinca transversal longa (CNT, 2018a). Adlinge e Gupta (2013) acrescentam que essas trincas se formam em ângulos aproximadamente retos em relação à linha central da pista, sendo espaçados regularmente.

Dentre outros fatores que podem ocasionar as trincas transversais, DNIT (2005) cita alta variação de temperatura, envelhecimento do asfalto e a propagação de trincas presentes nas camadas inferiores, principalmente em bases cimentadas ou em juntas de revestimento rígido. Assim, as principais causas das trincas transversais não estão racionadas diretamente com as tensões geradas pelas rodas dos veículos, no entanto, à ação do tráfego e a infiltração da água no revestimento contribuem para maior degradação em um período de tempo menor que o previsto.

\section{TRINCA LONGITUDINAL}

É uma trinca isolada que se manifesta paralela ao eixo da via. Sendo que, quando essa trinca aparecer com extensão de até um metro é chamada trinca longitudinal curta e quando a extensão for superior a um metro é chamada trinca longitudinal longa (CNT, 2018a). Para Bernucci et al., (2008), entender a causa é fundamental para selecionar o reparo adequado, sendo que muitas trincas paralelas podem eventualmente se formar a partir de uma fissura inicial.

DNIT (2005) traz que os fatores que ocasionam essa patologia não estão racionados diretamente com as tensões geradas pelas rodas dos veículos, no 
entanto, à ação do tráfego e a infiltração da água no revestimento contribuem para maior degradação em um período de tempo menor que o previsto. Com isso, os principais causadores desses defeitos são: falhas executivas, na temperatura de compactação ou mesmo na dosagem da mistura asfáltica; envelhecimento de ligante asfáltico; recalques diferenciais; falha de juntas longitudinais de diferentes frentes de compactação (BERNUCCl et al., 2008).

\section{TRINCA DE BORDO}

Em conformidade com DNIT (2005), é um defeito isolado caracterizado por uma trinca longitudinal ou por uma área trincada acompanhada por desintegração ou erosão no decorrer da borda da pista ou no acostamento. Na maioria dos casos, a trinca de bordo se encontra separada de no máximo $60 \mathrm{~cm}$ da margem do pavimento ou da região divisória em que o pavimento foi alargado.

A utilização de materiais adequados e uma boa execução dos serviços podem contribuir para a inexistência dessa patologia, pois suas principais causas estão relacionadas diretamente com a construção defeituosa entre a união da pista com o acostamento, diferença de rigidez entre os materiais utilizados no acostamento, alargamento e pavimento existente, falta de compactação e, ainda, a falta ou insuficiência de drenagem (DNIT, 2005).

\section{TRINCA POR REFLEXÃO}

Para DNIT (2006b), as trincas por reflexão ocorrem quando existem trincas nas camadas inferiores que se alastram em direção ao revestimento e o mesmo padrão que o defeito apresenta nas camadas inferiores é mantido em sua reflexão na superfície, sendo capaz de se manifestar em formato de trinca longitudinal, irregular ou interligada. Bernucci et al., (2008) acrescem que, geralmente, essas trincas são causadas pela reflexão de placas de concreto de cimento Portland.

A ação do tráfego próximo ou sobre uma trinca existente é um fator determinante para o desenvolvimento dessa patologia, dependendo das tensões aplicadas, a propagação de uma trinca por reflexão pode variar em uma velocidade entre $20 \mathrm{~mm}$ e $50 \mathrm{~mm}$ por ano, tendo assim, como principal consequência a redução da vida de fadiga do revestimento de forma significativa (DNIT, 2006b).

\section{TRINCA EM BLOCOS}

Como o próprio nome indica, segundo DNIT (2005), a trinca em bloco é um defeito que apresenta formato bem definido de "blocos" compostos, constituindose por diversas trincas interligadas com lados bem definidos e aspecto mais ou menos retangular, podendo, ou não, exibir erosões acentuadas nas bordas.

A principal causa dessa patologia é a alta variação de temperatura e a ligação entre trincas longitudinais e transversais. A existência desse defeito mostra que o ligante asfáltico não manteve sua característica elástica. Assim, com o passar do tempo, os blocos apresentam maior redução nas suas dimensões e consequentemente um aumento significativo em suas quantidades (DNIT, 2005). Essas, quando localizadas em tratamento superficial, são causadas pela reflexão 
de trincas em solo-cal da base, podendo apresentar erosão junto às bordas (BERNUCCl et al., 2008).

\section{TRINCA COURO DE JACARÉ}

É um defeito que se apresenta no pavimento por meio de trincas interligadas, sem direções preestabelecidas, e como próprio nome sugere, o formato é parecido com um couro de jacaré ou crocodilo, dependendo da severidade, existirá erosão nas bordas (DNIT, 2005). Adlinge e Gupta (2013) descrevem que as rachaduras levam à desintegração da superfície, ocasionando o surgimento de buracos. Essa trinca, geralmente, está associada a problemas de base ou drenagem.

DNIT (2006b) comenta que tais trincas se apresentam no pavimento devido à fadiga do revestimento asfáltico, ocasionada por carregamentos sucessivos. Sendo uma patologia que pode ocorrer em qualquer área do revestimento, porém, apresenta-se em locais com maior índice de tensões (trilhas de rodas). Além disso, Bernucci et al., (2008) alegam outros fatores que ocasionam esses defeitos, entre eles: ação climática - gradientes térmicos; envelhecimento do ligante e perda de flexibilidade; compactação deficiente do revestimento.

\section{AFUNDAMENTO DE TRILHA DE RODA}

Conforme DNIT (2005), o afundamento de trilha de roda pode ser dividido em dois tipos. O primeiro denomina-se afundamento por consolidação, que se caracteriza por ser um abatimento na trilha de roda, menos perceptível do que o afundamento plástico, pois a ocorrência não apresenta nenhuma mudança brusca nas laterais da pista. No início, essa patologia só fica mais percebível em dias chuvosos, em que as irregularidades ficam preenchidas por água.

Os principais motivos para ocorrência do afundamento por consolidação são a compactação insuficiente de alguma camada do pavimento, mistura asfáltica inadequada e enfraquecimento de uma ou mais camadas por causa da infiltração de água (DNIT, 2005).

No segundo caso, denomina-se afundamento plástico, diferente do afundamento por consolidação, o afundamento plástico além de apresentar uma depressão formada na trilha, há também a formação de um solevamento na lateral da pista. É um defeito que começa com a ruptura de uma ou mais camadas do pavimento, ocasionando a elevação lateral da pista devido à movimentação dos materiais, na qual fica visível a ruptura por afundamento plástico (DNIT, 2005).

\section{ONDULAÇÃO OU CORRUGAÇÃO}

É um defeito que tem como peculiaridade pequenos desvios com formato de minúsculas ondas de amplitude irregular, geralmente na posição longitudinal ao pavimento, algumas vezes, é acompanhado por escorregamentos do revestimento (CNT, 2018a).

DNIT (2005) alude que os principais motivos que causam esse defeito são a instabilidade da mistura betuminosa, instabilidade da base, excesso de umidade nas camadas inferiores, contaminação e retenção de água na mistura asfáltica. 
Tal patologia se apresenta com maior frequência nas regiões de aceleração e frenagem dos veículos, como por exemplo, locais próximos à lombada e parada de ônibus.

\section{ESCORREGAMENTO}

É a movimentação do revestimento em consideração as camadas inferiores do pavimento, e a principal característica é o surgimento de trincas em figura de meia-lua. Os principais motivos para ocorrência desse defeito é a ligação inadequada entre revestimento e a camada inferior, compactação inadequada da mistura asfáltica ou da parte superior da camada de base e, ainda, a fluência plástica do revestimento sob a alta variação de temperatura (DNIT, 2005).

Assim como a ondulação, o escorregamento é constantemente encontrado em trechos com grande índice de aceleração e frenagem de veículos, como nas rampas acentuadas, curvas horizontais de raio pequeno, interseções e próximo às paradas de ônibus ou lombadas (DNIT, 2005). Bernucci et al., (2008) citam como causador desse problema a falha na dosagem de mistura; falha na seleção de tipo de revestimento asfáltico.

\section{EXSUDAÇÃO}

DNIT (2005) adverte que é uma patologia em que a película ou filme de material betuminoso amplia-se na superfície do pavimento, sendo gerada por causa do deslocamento do ligante através do revestimento, formando manchas de diferentes dimensões. Tal movimentação do ligante pode ser ocasionada pela dosagem inadequada da mistura asfáltica e temperatura do ligante asfalto acima da especificada. Não há local determinado para a ocorrência desse defeito, porém, constantemente, a exsudação se apresenta nas trilhas de rodas. Além disso, Bernucci et al., (2008) acrescentam como fatores que podem ocasionar essa patologia: a segregação de massa, cravamento de agregados em base e ascensão de ligante à superfície.

\section{DESGASTE}

É um defeito que se caracteriza pelo arrancamento do agregado ou da argamassa fina do revestimento, tornando a superfície do pavimento visivelmente áspera. Essa aspereza aparente é muito significativa, em consequência dos esforços tangenciais provocados pelos veículos. Dentre outras causas, o desgaste ocorre pela diminuição da ligação e perda da adesividade entre o agregado e o ligante, execução da obra em condições climáticas inadequadas, presença de água no interior do revestimento e, ainda, falhas com o manuseio do ligante asfáltico nos serviços por penetração (DNIT, 2005).

\section{BURACO OU PANELA}

É uma irregularidade que se apresenta por meio de cavidades formadas inicialmente no revestimento do pavimento, possuindo dimensões e profundidades variadas, sendo que prejudica estruturalmente o pavimento e ocasiona a entrada de água nas camadas subjacentes (DNIT, 2005). A maioria dos buracos não 
ocorreria se fossem realizados os serviços de manutenção para reparar as fissuras que ocorrem no revestimento (ADLINGE; GUPTA, 2013).

Dentre outros motivos, os buracos podem existir por causa do trincamento por fadiga na fase final e pela desintegração fixada na superfície do pavimento, ou seja, no decorrer do tempo, as trincas se interligam, formando pequenas placas sem vínculo e com bordas erodidas e, assim, sem o devido tratamento, poderá formar grandes buracos no revestimento asfáltico que possibilitam a infiltração da água (DNIT, 2005).

\section{REMENDO}

Segundo DNIT (2005), é a correção do defeito no pavimento em um ponto localizado, tendo por objetivo a substituição de alguma irregularidade. Visto que, a área que apresenta o defeito deve ser substituída por material igual ou similar, apresentando-se em formato retangular. Paralelamente, Adlinge e Gupta (2013) descrevem o remendo como uma parte do pavimento que foi removida e substituída, servindo para reparar patologias no pavimento ou para cobrir uma vala de serviço público.

Geralmente, a existência do remendo na rodovia é avaliada como uma falha no pavimento, já que a execução ocasiona o mau funcionamento da estrutura original, gerando irregularidade longitudinal e consequentemente desconforto ao usuário. Dependendo da profundidade atingida pelo remendo, este pode ser classificado em remendo superficial e profundo. O primeiro é quando houver apenas correção do revestimento e o segundo aquele que há substituição do revestimento e, eventualmente, de uma ou mais camadas inferiores do pavimento (DNIT, 2005).

Não existem soluções específicas de M\&R para os remendos, no entanto, DNIT (2005) menciona que tais áreas só se tornam exatamente um defeito quando vierem causar desconforto ao usuário. Entretanto, a qualidade dos remendos depende da solicitação dos veículos, uso de material de qualidade duvidosa, grandes solicitações ambientais e, ainda, problemas na execução.

\section{DESNÍVEL ENTRE A PISTA E O ACOSTAMENTO}

É um defeito fácil de ser verificado, porque apresenta um desnível entre pista e acostamento, que aumenta na medida em que se alteram as condições do acostamento. As principais causas são o recalque do acostamento, perda de finos do acostamento, perda de material superficial gerado por intempéries em acostamentos não pavimentados, erros na execução e, também, problemas na execução de recapeamentos (DNIT, 2005).

\section{BOMBEAMENTO}

Normalmente localiza-se próximo às trincas ou juntas de construção, tendo como principal característica a erupção de água e finos nas trincas quando a rodovia está exposta a ação de cargas. Sendo provocado pela ocorrência de vazios abaixo do revestimento e por cargas geradas pelos veículos, tal defeito fica perceptível com a ocorrência de manchas no revestimento ou acumulação de material fino junto às trincas (DNIT, 2005). 


\section{ATIVIDADES DE MANUTENÇÃO E RESTAURAÇÃO (M\&R)}

Para Bernucci et al., (2008) a restauração só é necessária quando existirem problemas estruturais, entretanto, para solucionar patologias funcionais superficiais, são utilizados a execução dos revestimentos a seguir: lama asfáltica (selagem de trincas e rejuvenescimento); tratamento superficial simples ou duplo (selagem de trincas e restauração da aderência superficial); microrrevestimento asfáltico a frio ou a quente (selagem de trincas e restauração da aderência superficial quando existe condição de ação abrasiva acentuada do tráfego); concreto asfáltico (quando o defeito funcional principal é a irregularidade elevada); mistura do tipo camada porosa de atrito, SMA ou misturas descontínuas (para melhorar a condição de atrito e o escoamento de água superficial).

Paralelamente, para DNIT (2018) uma rodovia em condições ideais não tem buracos, rara incidência de remendos e/ou trincas; tem canteiros centrais e áreas vegetais laterais podadas; e sinalização visível. Para isso, destaca-se que o pavimento rodoviário é dimensionado de acordo com tráfego previsto para um período de projeto, denominado de ciclo de vida.

$\mathrm{Na}$ terça parte do ciclo de vida de um pavimento, as rodovias bem projetadas e executadas sofrem um degaste muito pequeno, porém, após esse período, se não forem feitas as devidas intervenções, ocorrerá à aceleração da degradação da via, possibilitando um mau estado de trafegabilidade. (DNIT, 2006b). No Gráfico 1 verifica-se que no decorrer do tempo, o pavimento vai se deteriorar e manifestar diversos defeitos, no entanto, para que essa deterioração evolua dentro do previsto, é necessária à execução dos serviços de manutenção preventiva e/ou corretiva, aumentando assim, a serventia do pavimento (DNIT, 2005).

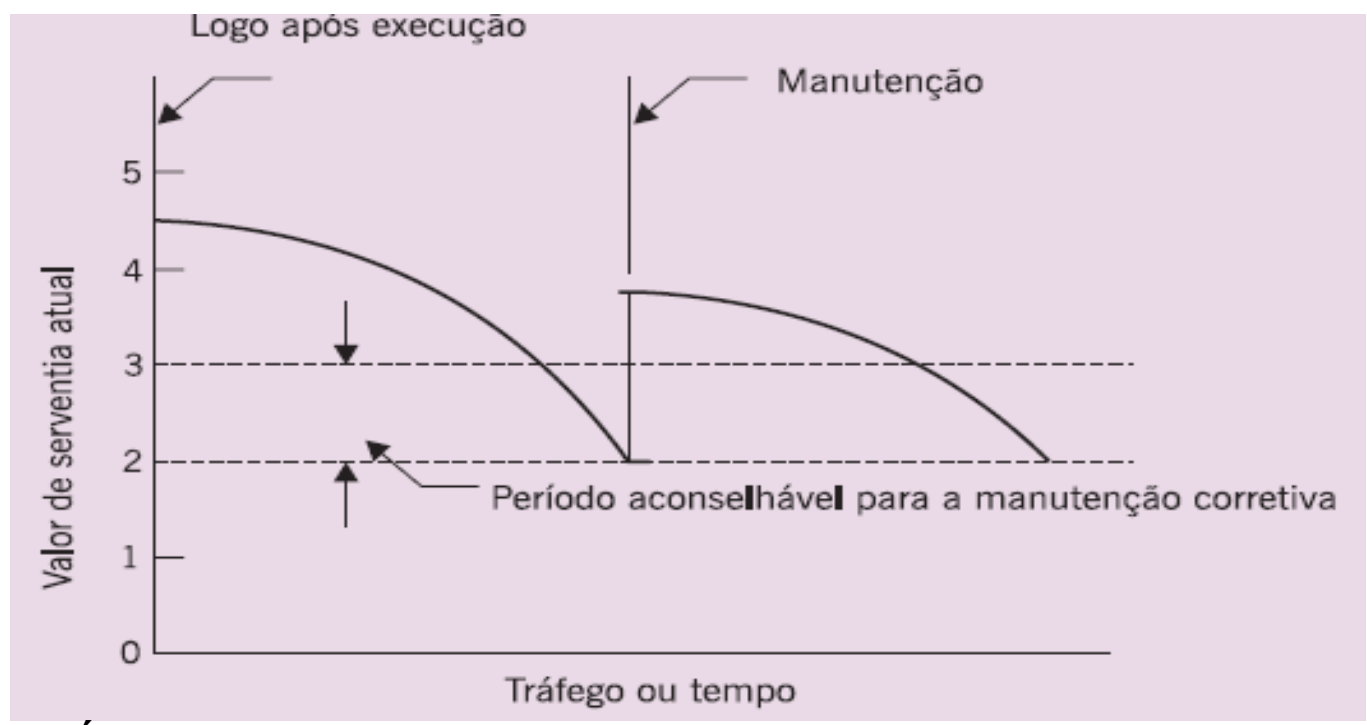

GRÁFICO 1 - Período recomendado para a manutenção dos pavimentos

Fonte: Bernucci et al., (2008)

À medida que o ciclo de vida do pavimento vai acabando, o Nível de Esforço (NE) para mantê-lo em um bom estado de funcionamento tende a 
aumentar. Um exemplo é a execução de tapa-buracos que tem o limite máximo em $10 \mathrm{~m}^{3} / \mathrm{km}$. Ano. Assim, quando as medidas preventivas e corretivas ultrapassarem o limite de custo-benefício, será necessária sob o ponto de vista técnico-econômico a execução da restauração, que tem como base um projeto de engenharia. Tal restauração compreende um serviço que tem como finalidade permitir que o pavimento existente tenha um novo aporte estrutural, possibilitandoo iniciar um novo ciclo de vida. A restauração torna-se essencial quando as soluções preventivas e corretivas não conseguem mais suprir as demandas da rodovia, e apesar de tais serviços serem de caráter periódico, não se enquadram como serviços de conservação (DNIT, 2005).

Para ODA (2016), a grande quantidade de elementos coletados no decorrer da vida útil de uma rodovia é fundamental para futuras atividades $M \& R$. Fernandes (2017) acrescenta que, em relação aos custos das atividades de $M \& R$, tem função essencial no planejamento e no sistema de gerência. Porquanto, com as estimativas dos custos, é definir quais serviços podem ser realmente executados, determinando os trechos prioritários. Sendo que os pavimentos rodoviários simulam um objeto de grande valor cuja conservação adequada é indispensável para a preservação. Qualquer suspensão ou diminuição na magnitude ou na constância das atividades necessárias à manutenção e restauração desse patrimônio provocará em acréscimos nos preços de operação dos veículos e na necessidade de investimentos maiores para a restruturação (CONSÓRCIO DYNATEST ENGEMAP, 2015).

Em concordância com DNIT (2006b), serão citados como manutenção os serviços preventivos e corretivos e como restauração os serviços de reforço e reconstrução. Porém, vale lembrar que o termo restauração substituiu o termo reabilitação no Manual do DNIT de Restauração de Pavimentos Asfálticos.

\section{MANUTENCÃO PREVENTIVA}

DNIT (2007) menciona que a manutenção preventiva tem como finalidade impedir aparecimento ou agravamento de falhas na estrutura do pavimento. Essa intervenção refere-se a atividades realizadas em períodos predeterminados de acordo com critérios técnicos. Assim, duas formas de conservação podem ser incluídas dentro da manutenção preventiva: a conservação preventiva periódica e a conservação rotineira.

No primeiro caso, DNIT (2007) descreve que é uma intervenção efetuada periodicamente, estando diretamente ligada à ação do trânsito, topografia do terreno e clima. Lado a lado, DNIT (2005) acrescenta que os serviços realizados nesse tipo de conservação são muitos, porém, os principais estão relacionados com a execução de uma nova camada asfáltica de pequena espessura, não sendo adicionada nenhuma contribuição estrutural significativa, ou seja, é adicionada uma sensível melhoria na serventia do pavimento, aumentando a vida útil. Ressalva-se que mesmo atingindo espessuras de até $4 \mathrm{~cm}$, tais camadas não tem a finalidade de melhoramento estrutural.

Destarte, as principais atividades periódicas executadas para melhorias do revestimento são a capa selante, lama asfáltica, camada porosa de atrito e recapeamento esbeltos com misturas densas. Algumas das principais metas da 
conservação periódica são: melhoria da superfície extremamente deteriorada, selagem das trincas, impermeabilização do pavimento, melhoria das propriedades de drenagem e atrito do revestimento, reparo/prevenção da deterioração e oxidação do pavimento, melhoria do aspecto do revestimento e proporcionar uma visão adequada no que diz respeito à demarcação entre pista e acostamento (DNIT, 2005).

Já o segundo caso de conservação, DNIT (2007) cita que se encaixa dentro da definição de manutenção preventiva, porque é uma operação que tem como principais objetivos a manutenção do sistema de drenagem, das faixas laterais à rodovia, dos taludes laterais, dos elementos de sinalização e, ainda, sanar defeitos de até 1,5 metros que poderão ocorrer na pista ou no acostamento.

São muitas as soluções preventivas existentes, porém, as execuções dependem de fatores relacionados às particularidades do pavimento, tráfego atuante e disponibilidade de materiais e equipamentos. Apesar de muitas vezes consistir apenas em soluções paliativas, a manutenção preventiva desempenha um papel fundamental no que se refere à conservação das rodovias, porquanto poderá melhorar o desempenho do pavimento e, consequentemente, reduzir gastos posteriores. De tal modo, percebe-se que a manutenção preventiva tem como alvo principal não de reparar defeitos apresentados na rodovia, mas, sim, impedir que as patologias venham a ocorrer (DNIT 2005).

\section{MANUTENÇÃO CORRETIVA}

Manutenção corretiva é a intervenção que tem como finalidade reparar ou eliminar um defeito no pavimento, proporcionando maior conforto e segurança aos usuários da via, isto é, melhorando o funcionamento dos elementos que compõem à rodovia (DNIT, 2007). Desse modo, diferentemente da manutenção preventiva, as intervenções corretivas, além de melhorar a qualidade de rolamento, contribuem para restaurar a capacidade estrutural da rodovia (DNIT, 2005).

DNIT (2005) estabelece que a manutenção corretiva seja executada pelos responsáveis pela rodovia na forma de conservação corretiva rotineira. Tal conservação é definida como um procedimento aplicado a um pavimento desgastado, com a finalidade de restabelecer características obtidas na construção.

Os principais tipos de manutenção corretiva são: remendo profundo, selagem de trinca, tapa buraco, recapeamentos asfálticos (reconformação), limpeza e restruturação do sistema de drenagem, renovação de sinalização horizontal e vertical, recomposição do guarda corpo e defensa metálica. Para um melhor planejamento da manutenção corretiva é necessário saber quais e quantos são os elementos causadores dos problemas, além da amplitude da execução dos reparos. Logo depois, é possível planejar e programar os tipos e quantidades de serviços a serem executados no decorrer de um período predeterminado (DNIT, 2005).

\section{REFORÇO ESTRUTURAL}

O reforço é um apoio estrutural, composto de uma ou mais camadas betuminosas, executadas sobre um pavimento existente devidamente preparado 
para receber tais intervenções. Ocasionalmente, dependendo de critérios técnicos, o reforço poderá ser executado sobre uma camada granular. Dessa maneira, o reforço consiste basicamente na execução de um recapeamento que pode ser de mistura asfáltica e/ou concreto de cimento Portland. Tal operação é realizada de acordo com a necessidade de suporte, e tem como objetivo o retorno da qualidade de rolamento e da capacidade estrutural, esta é indispensável para que a estrutura resista aos esforços gerados pelo tráfego durante um período prefixado, iniciando assim, um novo ciclo de vida (DNIT, 2006b).

DNIT (2005) determina que a execução do reforço é uma medida definida previamente em projeto de restauração do pavimento e para o dimensionamento é necessário à projeção do VMD, carregamento da frota e cálculo do Número N. O Gráfico 2 exibe que a degradação da rodovia segue uma trajetória não linear, e a necessidade da execução do reforço ocorre em um período em que as operações corretivas de menor dimensão não conseguem mais conter o processo evolutivo de degradação da rodovia.

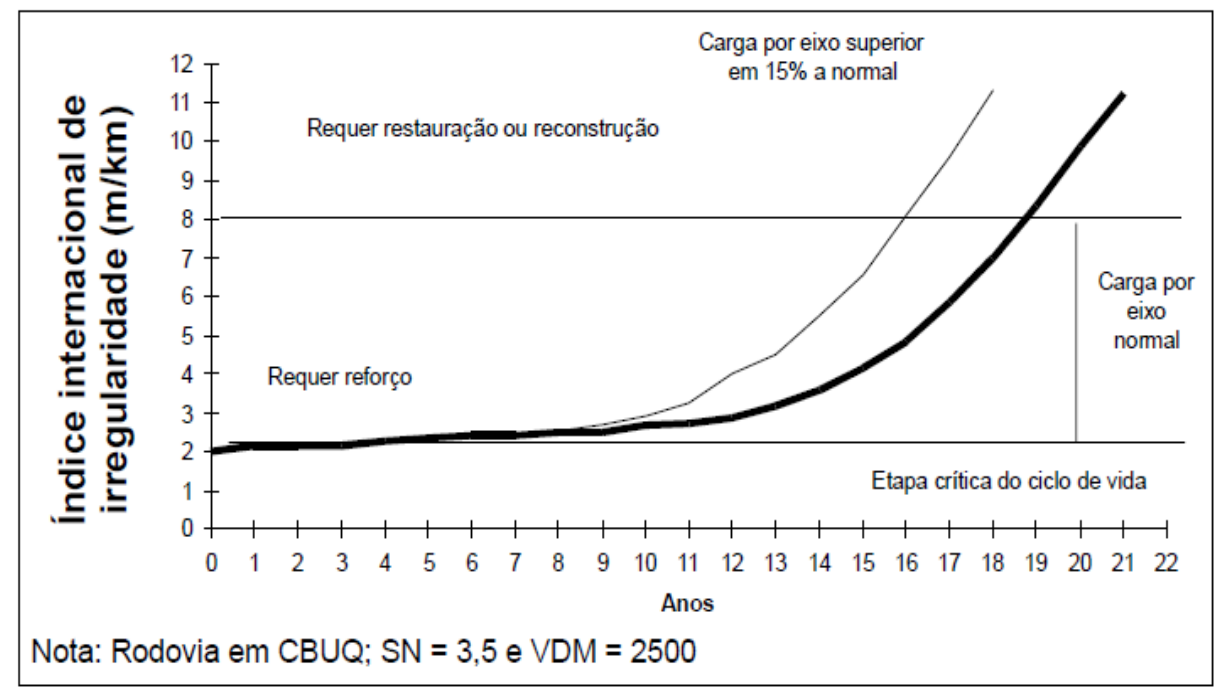

GRÁFICO 2 - Evolução da deterioração em pavimentos rodoviários Fonte: DNIT (2006b)

Balbo (2007) descreve que o reforço de pavimento é capaz de proporcionar uma alta resposta estrutural, e possibilita obter uma melhor condição de rolamento aos usuários. Ao se tratar de reforço de camadas asfálticas, são formadas por misturas asfálticas, devendo ser dimensionadas de acordo com a expectativa de tráfego designada em projeto.

Dependendo das características dos materiais utilizados, espessura da capa e propriedades das misturas, o reforço está exposto ao desenvolvimento de trincas geradas principalmente pelas baixas temperaturas, ciclos de variação diária da temperatura e carregamento do tráfego. Então, para evitar problemas gerados pela propagação de trincas, é aplicado um elemento sob o reforço com o propósito de torná-los mais flexíveis, evitando à reflexão de trincas, os principais 
elementos utilizados são: geotêxteis, camadas de alívio de tensões e camadas de interrupção do trincamento (DNIT, 2005).

Ressalva-se em DNIT (2006b) que não existe uma concordância sobre o dimensionamento de reforço de pavimentos asfálticos, há uma grande quantidade de métodos empregados por órgãos rodoviários. Genericamente, o método mais utilizado é similar ao projeto de um novo pavimento, exceto que leva em consideração a qualidade atual ou a vida remanescente do pavimento existente.

Embora o custo de utilização de novas tecnologias para estudos prévios do pavimento seja maior, tais ferramentas utilizadas tanto no dimensionamento de novas vias quanto para o reforço de pavimentos existentes, são fundamentais, pois podem especificar as espessuras necessárias das camadas do pavimento a serem aplicadas e o tipo de revestimento que proporcionará melhor desempenho e, ainda, possibilita uma previsão no surgimento de possíveis fissuras (CNT, 2018b).

\section{RECONSTRUÇÃO}

É uma operação determinada em projeto de engenharia relativa à restauração e/ou reabilitação do pavimento, uma vez que, na execução é removida a espessura total ou parcial do pavimento, e dependendo da necessidade de projeto poderá adentrar até o subleito. Tal intervenção tem por finalidade a implantação de novas camadas estruturais, cujas constituições e especificações devem manter as características das áreas adjacentes do pavimento restante (DNIT, 2005). Conjuntamente, DNIT (2007) alude que a reconstrução possibilita o início de um ciclo de vida ao pavimento, visto que, é um conjunto de atividades com o intento de reestruturar o pavimento, fazendo com que a estrutura possa suportar a repetição de cargas na qual for solicitada, possibilitando melhor qualidade de segurança e conforto aos usuários.

$\mathrm{Na}$ reconstrução parcial a espessura tirada e substituída se restringe a uma profundidade que não atinge a espessura total do pavimento e na reconstrução total a espessura tirada e substituída alcança toda a espessura do pavimento, podendo, ocasionalmente, alcançar o subleito como mencionado anteriormente (DNIT, 2006b).

DNIT (2005) também afirma que se houver aplicação dos serviços de manutenção preventiva e corretiva de forma adequada e, ainda, se o serviço de reforço for devidamente projetado e executado, uma rodovia nunca chegará a um mau estado de funcionamento, ou seja, não será necessária à execução da reconstrução do pavimento, evitando assim, custos relativamente mais elevados.

\section{CONSIDERAÇÕES FINAIS}

Neste trabalho foi realizada uma pesquisa puramente bibliográfica com a finalidade de destacar as principais patologias (defeitos) localizadas em pavimentos flexíveis e semirrígidos. Foram demonstradas as principais atividades de Manutenção e Restauração $(M \& R)$ aplicadas para a restruturação de pavimentos danificados.

Dessa forma, o objetivo principal do estudo foi alcançado, pois a reunião de forma descritiva dos defeitos possibilita uma análise precisa, no meio acadêmico, 
para futuras vistorias e estudos realizados em campo. Além disso, a descrição inicial sobre os pavimentos existentes no Brasil tornou a análise ainda mais clara, o que possibilita caracterizar os principais materiais e camadas utilizadas na construção de novas vias.

Apesar das informações contidas na pesquisa não serem apresentadas de forma ampla, é citado para cada patologia apresentada, as possíveis causas e as principais soluções aplicadas no mercado brasileiro. Para isso, tem-se o entendimento de que este trabalho é uma contribuição de forma específica que apresenta informações precisas referentes aos defeitos catalogados por órgãos do setor público e privado.

Entretanto, no que se refere às atividades de $M \& R$ esta pesquisa mostra os principais métodos utilizados no combate de patologias em pavimentos flexíveis e semirrígidos, destacando que existe uma aceitação na aplicação de normas do DNIT por maior parte dos autores estudados, ou seja, apesar de algumas discordâncias, os métodos utilizados são basicamente os mesmos em todo o território do Brasil.

Com isso, o estudo mostrou a diferença entre a classificação das rodovias; as principais patologias nos pavimentos flexíveis e semirrígidos e, ainda, descreveu de forma resumida as atividades de M\&R aplicadas no setor rodoviário até $o$ atual momento. Dessa maneira, conclui-se que este trabalho apresenta de forma simples e clara um assunto que é tão importante no cenário nacional, entretanto, apesar do não aprofundamento no tema, tal pesquisa possibilita estudos futuros por parte de técnicos dispostos a continuarem contribuindo com 0 desenvolvimento deste setor, que é tão carente no território brasileiro.

\section{REFERÊNCIAS}

ADLINGE, S. S.; GUPTA, A. K. Pavement Deterioration and its Causes. Índia, 2013. Disponível em: <http://iosrjournals.org/iosr-jmce/papers/sicete(civil) volume6/60.pdf>. ISSN: 2278-1684. Acesso em 25/09/2019.

BALBO, J.T. Pavimentação asfáltica: materiais, projeto e restauração. São Paulo: Oficina de Textos, 2007.

BERNUCCI, L. B.; MOTTA, L. M. G.; CERATTI, J. A. P.; SOARES, J. B. Pavimentação asfáltica: formação básica para engenheiros. 1. ed. Rio de Janeiro, PETROBRAS: ABEDA, 2008.

CNT - Confederação Nacional de Transportes. Transportes rodoviários: por que os pavimentos das rodovias do Brasil não duram?. Confederação Nacional de Transportes. 2017.

CNT - Confederação Nacional de Transportes. Transporte Rodoviário: Impactos da qualidade do asfalto sobre o transporte Rodoviário. Confederação Nacional de Transportes. 2019. Disponível em: <https://cnt.org.br/impactos-qualidade-asfaltotransporte-rodoviario >. Acesso em 05/06/2019 
CNT - Confederação Nacional de Transportes. Conheça os 13 principais defeitos do pavimento das rodovias. Confederação Nacional de Transportes. 2018a. Disponível em: <https://www.cnt.org.br/agencia-cnt/conheca-principaisdefeitos-pavimento >. Acesso em 13/06/2019

CNT - Confederação Nacional de Transportes. DNIT deve implementar novo método de pavimentação asfáltico. Confederação Nacional de Transportes. 2018b. Disponível em: <https://www.cnt.org.br/agencia-cnt/novo-metodopavimentacao-asfaltica-dnit-breve>. Acesso em 05/06/2019

CNT - Confederação Nacional de Transportes. Pesquisa CNT de rodovias 2018: relatório gerencial. Confederação Nacional de Transportes. 2018c. Disponível em: <https://cms_pesquisarodovias.cnt.org.br//Relatorio\%20Geral/Pesquisa\%20CNT\% 20de\%20Rodovias\%202018\%20-\%20web\%20-\%20baixa.pdf>. Acesso em 09/06/2019

CONSÓRCIO DYNATEST ENGEMAP. Relatório técnico: catálogo de soluções de manutenção para pavimentos flexíveis. 2015.

DNIT - Departamento Nacional de Infraestrutura de Transportes. ICM 2018. 2018. Disponível em: <http://www.dnit.gov.br/noticias/icm-2018-indice-que-avalia-asrodovias-federais-pavimentadas-e-divulgado>. Acesso em 08/05/2019

DNIT - Departamento Nacional de Infraestrutura de Transportes. Manual de conservação rodoviária. Rio de Janeiro, 2005.

DNIT - Departamento Nacional de Infraestrutura de Transportes. Manual de pavimentação. Rio de Janeiro, 2006a.

DNIT - Departamento Nacional de Infraestrutura de Transportes. Manual de restauração de pavimentos asfálticos. Rio de Janeiro, 2006b.

DNIT - Departamento Nacional de Infraestrutura de Transportes. Terminologias rodoviárias usualmente utilizadas. 2007.

DYNATEST. Tipos de patologia do asfalto em rodovias. 2017. Disponível em: $<$ http://dynatest.com.br/tipos-de-patologia-do-asfalto-em-

rodovias/\#targetText=Falhas\%20em\%20cada\%20uma\%20dessas,as\%20patologia s\%20dos\%20pavimentos\%20asf\%C3\%A1lticos.\&targetText=Os\%20principais\%20 tipos\%20de\%20patologia,\%2C\%20deforma\%C3\%A7\%C3\%B5es\%2C\%20panelas $\% 20$ e\%20remendos. >. Acesso em 17/06/2019

FERNANDES, F. M. L. da S. Software de gerenciamento de pavimentos aplicado a vias urbanas de cidades de pequeno a médio porte. Projeto de Graduação. Departamento de Engenharia de Transportes. Curso de Graduação 
em Engenharia Civil. Universidade Federal do Rio de Janeiro. Rio de Janeiro, 2017.

ODA, S. Notas de Aula. Disciplina EER 555 Pavimentação A. Departamento de Engenharia de Transportes. Escola Politécnica da Universidade Federal do Rio de Janeiro - UFRJ, 2016.

ZOFKA, A. Proactive pavement asset management with climate change aspects. Warszawa, 2018. Disponível em: <https://iopscience.iop.org/article/10.1088/1757-899X/356/1/012005>. doi:10.1088/1757-899X/356/1/012005. Acesso em 07/02/2019. 